\title{
Pb Removal Using Mixed Substrates in a Constructed Laboratory-Scale Unvegetated Vertical Subsurface-Flow Wetland
}

\author{
Jun Ren ${ }^{1,2 *}$, Suxia Gao ${ }^{1,2}$, Ling Tao ${ }^{1,2}$, Hua Li ${ }^{1,2}$ \\ ${ }^{1}$ School of Environmental and Municipal Engineering. Lanzhou Jiaotong University, \\ Lanzhou 730070, Lanzhou, 730070, P. R. China \\ ${ }^{2}$ Engineering Research Center for Cold and Arid Regions Water Resource Comprehensive Utilization, \\ Ministry of Education, \\ Lanzhou, 730070, P. R. China
}

Received: 29 August 2015

Accepted: 29 October 2015

\begin{abstract}
In this study, five mixed substrates - SSFGF, FSSGF, FSSFF, FSSFG, and FSFGF - consisting of fly ash, sludge, soil, fine cinder, gravels, and fine sand, were made in order to test the removal effect of lead. Multiple comparisons and analysis of variance were used to analyze physicochemical properties and the removal efficiency of lead. The test results showed that for five substrates, the effluent concentrations were not significantly different among $10 \mathrm{mg} / \mathrm{L}$ and $40 \mathrm{mg} / \mathrm{L}$ initial concentrations. For the other three initial concentrations $(20 \mathrm{mg} / \mathrm{L}, 80 \mathrm{mg} / \mathrm{L}$ and $160 \mathrm{mg} / \mathrm{L})$ from five substrates, it was significantly different. Moreover, when decomposition time was $0.25 \mathrm{~h} \sim 48 \mathrm{~h}$, the removal efficiency of Pb from the solution was better for substrate SSFGF-based wetland than those of the other substrate-based wetlands at low and medium initial concentrations (10 mg/L, $20 \mathrm{mg} / \mathrm{L}, 40 \mathrm{mg} / \mathrm{L}$, and $80 \mathrm{mg} / \mathrm{L}$ ), and then it was slightly better for substrate FSSFF-based wetland. At relatively high initial concentrations $(160 \mathrm{mg} / \mathrm{L})$, the removal efficiency was better for substrate FSSFF-based wetland than those of the other substrate-based wetlands, and then it was slightly better for substrate SSGFF-based wetland. Our study further suggested that SSFGF and FSSFF were the two relatively ideal substrate materials suitable for removal of $\mathrm{Pb}$ from a constructed wetland system.
\end{abstract}

Keywords: wastewater, constructed wetland, lead, initial concentration, mixed substrate

\section{Introduction}

Lead is considered to be one of the most harmful heavy metals to the ecological system and human health. It is used as industrial raw material for storage battery

*e-mail:renjun@mail.lzjtu.cn manufacturing, printing, pigments, fuels, photographic materials, and explosive manufacturing. Industrialization has contaminated the environment with heavy metals, particularly in developing countries, where advance treatment technologies are neither available nor affordable. The constructed wetland, therefore, presents a cost-effective and promising alternative for the treatment of industrial effluents. 
Table 1. Packing configuration of vertical-flow constructed wetlands.

\begin{tabular}{|c|c|c|c|c|c|c|}
\hline Substrate & Fly ash & Sludge & Soil & Fine cinder & Gravel & Fine sand \\
\hline SSFGF & $0 \mathrm{~kg}$ & $130 \mathrm{~kg}$ & $230 \mathrm{~kg}$ & $160 \mathrm{~kg}$ & $310 \mathrm{~kg}$ & $286 \mathrm{~kg}$ \\
\hline FSSGF & $150 \mathrm{~kg}$ & $130 \mathrm{~kg}$ & $230 \mathrm{~kg}$ & $0 \mathrm{~kg}$ & $310 \mathrm{~kg}$ & $286 \mathrm{~kg}$ \\
\hline FSSFF & $150 \mathrm{~kg}$ & $130 \mathrm{~kg}$ & $230 \mathrm{~kg}$ & $160 \mathrm{~kg}$ & $0 \mathrm{~kg}$ & $286 \mathrm{~kg}$ \\
\hline FSSFG & $150 \mathrm{~kg}$ & $130 \mathrm{~kg}$ & $230 \mathrm{~kg}$ & $160 \mathrm{~kg}$ & $310 \mathrm{~kg}$ & $0 \mathrm{~kg}$ \\
\hline FSFGF & $150 \mathrm{~kg}$ & $130 \mathrm{~kg}$ & $0 \mathrm{~kg}$ & $160 \mathrm{~kg}$ & $310 \mathrm{~kg}$ & $286 \mathrm{~kg}$ \\
\hline
\end{tabular}

The use of constructed wetland systems to remove metals has become an area of interest to many researchers. Currently, constructed wetlands have been widely used to treat various kinds of wastewater such as municipal wastewater [1-3], agricultural wastewater [4], industrial wastewater [5-10], landfill leachate [11], and runoff [12]. The results have shown that constructed wetlands are very effective in removing heavy metals from polluted wastewaters that include aluminium, zinc, chromium, lead, cadmium, iron, nickel, chromium, and copper.

Constructed wetlands are engineered systems that have been designed to employ natural processes, including vegetation, soil, and microbial activity to treat contaminated water. Several studies have shown that many materials were used as filter media to treat wastewater polluted by heavy metals. It is reported that laterite was efficient in removing aluminium, iron, lead, cadmium, and chromium [13]. It has been shown that the systems had remarkable removal efficiencies on treating wastewater containing $\mathrm{Pb}, \mathrm{Zn}$, and $\mathrm{Cu}$ with coke and gravel as substrates [14]. In addition, a lab-scale study investigated the use of vertical subsurface-flow constructed wetlands for removing arsenic, boron, copper, zinc, iron, and manganese from synthetic wastewater in which gravel, limestone, zeolite, and cocopeat were employed as wetland media. The overall results demonstrated that alternative wetland media (cocopeat, zeolite, and limestone) showed significant higher efficiencies than that of the gravel media [15].

Some reports document the important role of the filling media that are capable of heavy metals removal, and proved that the plants did not contribute to total heavy metal removal to a higher extent [16]. The overall performance of a constructed wetland is, therefore, primarily dependent on the selection of suitable substrates.

The use of mixed substrates in constructed wetlands has been suggested by different researchers with the aim of improving removal performance. For example, it shows that six different packing orders of filter media, including gravel, sand, granular activated carbon, charcoal, and Filtralite (light expanded clay) were applied for the removal of lead and copper of simulating pretreated mine wastewater in vertical-flow wetlands [17]. Nevertheless, little research in this area has been reported. This study aims to explore the performance of five mixed substrates: fly ash, sludge, soil, gravel, fine cinder, and fine sand in the removal of $\mathrm{Pb}$ using vertical-flow constructed wetland systems and identifying some substrate configuration and optimal combination.

\section{Materials and Methods}

\section{Materials}

Six raw materials, namely fly ash, sludge, soil, gravel, fine cinder, and fine sand were selected for this study. Five of those were mixed together in a proportion of $20 \%$ each in volume to constitute a mixed substrate, and five different packing configurations of filter substrate were applied to the five vertical-flow wetland systems (Table 1). Soil was obtained from the campus of the school of environmental and municipal engineering of Lanzhou Jiaotong University, Lanzhou City, China; fine sand was obtained from Shapotou district, Ningxia Province; gravel was obtained from a construction site in Lanzhou city; fine cinder was obtained from a boiler room of Lanzhou Jiaotong University; sludge was obtained from a sewage treatment plant of Lanzhou; and fly ash was purchased.

\section{The Artificial Wastewater}

Experiments were carried out to treat artificial wastewater using five lab-scale mixed substrate beds. Aqueous solutions containing lead ions $\left(\mathrm{Pb}^{2+}\right)$ at various concentrations $(10 \mathrm{mg} / \mathrm{L}, 20 \mathrm{mg} / \mathrm{L}, 40 \mathrm{mg} / \mathrm{L}, 80 \mathrm{mg} / \mathrm{L}$, and $160 \mathrm{mg} / \mathrm{L}$ ) were prepared by dissolving lead nitrate $\left(\mathrm{Pb}\left(\mathrm{NO}_{3}\right)\right)$ powders in deionized water. $\mathrm{Pb}\left(\mathrm{NO}_{3}\right)$ was $\mathrm{AR}$ grade.

\section{The Lab-Scale Unvegetated Constructed Wetland Systems}

Five lab-scale constructed wetlands filled with five different substrates (mixed substrates) in Lanzhou Jiaotong University were constructed by PMMA with an external packed bed size of $0.8 \mathrm{~m} \times 1 \mathrm{~m} \times 1.12 \mathrm{~m}$ (length $\times$ width $\times$ height). Each unit had a $0.2 \mathrm{~m}$ deep drainage layer of stones at the base. The drainage layer was topped with a layer of mixed substrates that was $0.7 \mathrm{~m}$ deep. The bottom of each unit include installed polyvinylchloride pipe (PVC) of $0.019 \mathrm{~m}$ in diameter. The constructed wetlands were all fed with lead wastewater 
from the same source through flexible tubing $0.013 \mathrm{~m}$ in diameter from the top of the wetlands (Fig. 1).

During the study period, the mean hydraulic loading rate (HLR) was kept at $0.5 \mathrm{~m}^{3} / \mathrm{m}^{2} \cdot \mathrm{d}$. The experiment was operated in submerged flow under conditions of continuous feeding and discharging. After being treated by the constructed wetlands, the heavy metal wastewater flowed out of the system through the effluent pipe. The constructed wetland was refreshed with the same mixed substrates after treatment by one concentration.

\section{Experiment Methods and Instruments}

The total porosity (TP) and particle uniformity coefficients $\left(\mathrm{K}_{80}\right)$ of a substrate material can be calculated by the following equations:

$$
\begin{aligned}
\text { Total porosity }(\%)= & \left(1-\frac{\text { substrate bulk density }}{\text { substrate specific gravity }}\right) \times \\
& \times 100 \% \\
& \mathrm{~K}_{80}=\frac{\mathrm{D}_{80}}{\mathrm{D}_{10}}
\end{aligned}
$$

...where $\mathrm{D}_{10}$ and $\mathrm{D}_{80}(\mathrm{~mm})$ are the diameters of particle sizes of a substrate material at which $10 \%$ and $80 \%$ of the particles pass through the sieves based on the accumulative frequency, and $\mathrm{K}_{80}$ is the uniformity coefficient.

Hydraulic conductivity (HC) is determined by Darcy's law [18]:

$$
K_{c} \frac{Q}{A \cdot I \cdot T}
$$

... where $\mathrm{K}_{\mathrm{c}}$ is hydraulic conductivity $(\mathrm{mm} / \mathrm{min})$, $\mathrm{Q}$ is total water flow rate $\left(\mathrm{mm}^{3} / \mathrm{min}\right), \mathrm{A}$ is the area of the infiltration bed $\left(\mathrm{mm}^{2}\right)$, I is the water head gradient, and $\mathrm{T}$ is the

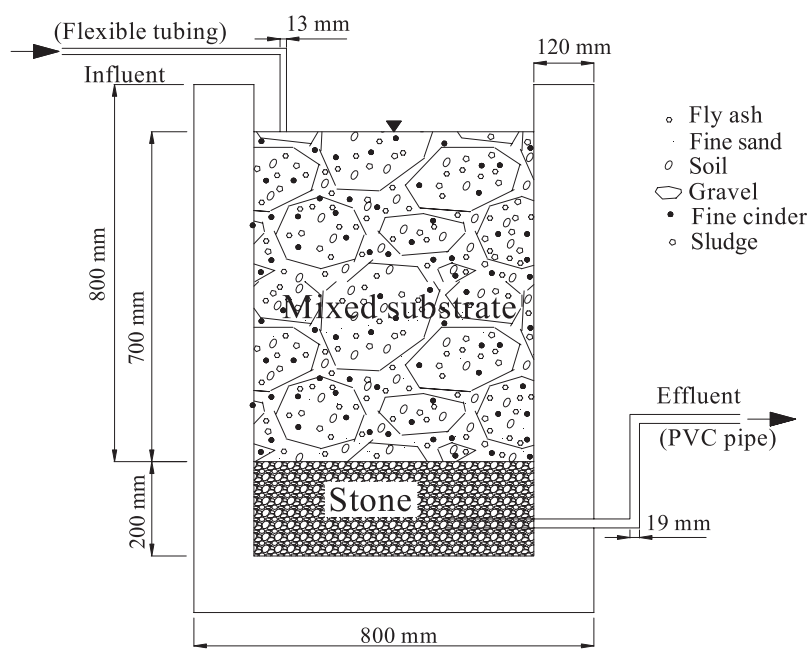

Fig. 1. Unvegetated experimental mixed substrates-based vertical subsurface flow constructed wetland. time (min). The parameter values in $\mathrm{K}_{\mathrm{c}}$ used to calculate the hydraulic conductivities of the five substrates were measured from Cui [19].

Organic matter $(\mathrm{OM})$ was measured by dichromate titration oxidation and volumetric procedure. The cation exchange capacity (CEC) was measured using the ammonium acetate method. Exchangeable $\mathrm{Ca}$ (E-Ca) and $\mathrm{Mg}(\mathrm{E}-\mathrm{Mg})$ were measured using an inductivelycoupled plasma atomic emission spectrometry method after extracting the soil sample with neutral ammonium acetate. Exchangeable Al (E-Al) was measured using an inductively-coupled plasma atomic emission spectrometry method after extracting the soil sample with potassium chloride. Active Fe (A-Fe) and Mn (A-Mn) were measured using an inductively coupled plasma atomic emission spectrometry method, after extracting soil samples with DTPA (diethlenetriaminepentaacetic acid), TEA (triethanolamine), and $\mathrm{CaCl}_{2}$. After fusion with sodium carbonate, the total content of $\mathrm{Ca}$ (T-Ca), $\mathrm{Mg}$ (T-Mg), Al (T-Al), Fe (T-Fe), and $\mathrm{Mn}(\mathrm{T}-\mathrm{Mn})$ in soils was measured using ICP.

Water samples were taken at the following time intervals: $0.25 \mathrm{~h}, 0.5 \mathrm{~h}, 1 \mathrm{~h}, 2 \mathrm{~h}, 4 \mathrm{~h}, 8 \mathrm{~h}, 12 \mathrm{~h}, 24 \mathrm{~h}$, and $48 \mathrm{~h}$. Lead concentrations were determined by ICP. The removal of $\mathrm{Pb}(\mathrm{RE})$ by a substrate was calculated using the following equation:

$$
\mathrm{Pb} \text { removal rate }(\%)=\frac{\mathrm{C}_{0}-\mathrm{C}_{\mathrm{e}}}{\mathrm{C}_{0}} \times 100 \%
$$

... where $\mathrm{C}_{0}$ is the initial $\mathrm{Pb}$ concentration and $\mathrm{C}_{\mathrm{e}}$ is the $\mathrm{Pb}$ concentration at $48 \mathrm{~h}$.

Concentrations of the metals were detected by inductively-coupled plasma atomic emission spectrometry (Varian, IRIS Intrepid II XSP, USA).

\section{Statistical Analyses}

Analysis of variance (ANOVA) for the data was performed on all data sets. Duncan's test was used to differentiate means where appropriate. A level of $p<0.05$ was used in all comparisons. Statistical analysis was performed using STATISTICA software.

\section{Results and Discussion}

\section{Physicochemical Properties of Substrates}

It was found that bulk density and specific gravity were not significantly different in the five substrates $(\mathrm{P}>0.05)$. Total porosity and Total Ca were significantly different in the five substrates $(\mathrm{P}<0.01)$. The other physicochemical properties were significantly different in the five substrates $(\mathrm{P}<0.001)$ (Table 2).

Hydraulic conductivity was not significantly different between FSSGF and FSSFF and was significantly lower than that in the other three substrates. It was significantly greater in SSFGF than those in FSSGF and FSSFF, and 
Table 2. Physicochemical properties of mixed substrates used in this study.

\begin{tabular}{|c|c|c|c|c|c|c|}
\hline Substrates & SSFGF & FSSGF & FSSFF & FSSFG & FSFGF & F-value \\
\hline Bulk density $\left(\mathrm{g} / \mathrm{m}^{3}\right)$ & 1.15 & 0.99 & 0.99 & 0.9 & 1.06 & 2.721 \\
\hline Specific gravity $\left(\mathrm{g} / \mathrm{m}^{3}\right)$ & 2.54 & 2.46 & 2.45 & 2.46 & 2.51 & 0.023 \\
\hline Hydraulic conductivity ( $\mathrm{mm} / \mathrm{min}$ ) (eq. 3 ) & $0.38^{\mathrm{a}}$ & $0.12^{\mathrm{b}}$ & $0.1^{\mathrm{b}}$ & $1^{\mathrm{c}}$ & $0.8^{\mathrm{d}}$ & $306.227^{* * *}$ \\
\hline Total porosity (\%) (eq. 1) & $58^{\mathrm{a}}$ & $67.24^{\mathrm{b}}$ & $67.21^{\mathrm{b}}$ & $70.07^{\mathrm{b}}$ & $58^{\mathrm{a}}$ & $5.840^{* *}$ \\
\hline $\mathrm{D}_{10}$ particle diameter $(\mathrm{mm})$ & $0.09^{\mathrm{a}}$ & $0.05^{\mathrm{b}}$ & $0.05^{\mathrm{b}}$ & $0.05^{\mathrm{b}}$ & $0.06^{\mathrm{c}}$ & $39.838^{* * *}$ \\
\hline $\mathrm{D}_{80}$ particle diameter $(\mathrm{mm})$ & $3.65^{\mathrm{a}}$ & $2.57^{\mathrm{b}}$ & $2.97^{\mathrm{c}}$ & $3.28^{\mathrm{d}}$ & $2.76^{\mathrm{e}}$ & $692.707^{* * *}$ \\
\hline $\mathrm{K}_{80}$ uniformity coefficient (eq. 2) & $42.94^{\mathrm{a}}$ & $51.4^{\mathrm{b}}$ & $59.4^{\mathrm{c}}$ & $65.6^{\mathrm{c}}$ & $46^{\mathrm{ab}}$ & $14.910^{* * *}$ \\
\hline $\mathrm{pH}$ & $8.27^{\mathrm{a}}$ & $10.63^{b}$ & $9.53^{\mathrm{c}}$ & $8.92^{\mathrm{d}}$ & $10.63^{b}$ & $85.388^{* * *}$ \\
\hline $\mathrm{CEC}(\mathrm{cmol} / \mathrm{kg})$ & $49.89^{\mathrm{a}}$ & $11.61^{\mathrm{b}}$ & $8.12^{\mathrm{b}}$ & $8.76^{\mathrm{b}}$ & $23.15^{\mathrm{b}}$ & $6.864^{* * *}$ \\
\hline Organic matter $(\mathrm{g} / \mathrm{kg})$ & $2.15^{\mathrm{a}}$ & $1.97^{\mathrm{a}}$ & $15.48^{\mathrm{b}}$ & $19.45^{\mathrm{c}}$ & $2.1^{\mathrm{a}}$ & $270.636^{* * *}$ \\
\hline Exchangeable $\mathrm{Ca}(\mathrm{cmol} / \mathrm{kg})$ & $0.23^{\mathrm{a}}$ & $0.16^{\mathrm{b}}$ & $0.14^{\mathrm{b}}$ & $0.34^{\mathrm{c}}$ & $0.34^{\mathrm{c}}$ & $346.061^{* * *}$ \\
\hline Exchangeable $\mathrm{Mg}(\mathrm{cmol} / \mathrm{kg})$ & $0.16^{\mathrm{a}}$ & $0.38^{\mathrm{b}}$ & $0.11^{\mathrm{c}}$ & $0.54^{\mathrm{d}}$ & $0.11^{\mathrm{c}}$ & $1447.653^{* * *}$ \\
\hline Exchangeable $\mathrm{Al}(\mathrm{mg} / \mathrm{kg})$ & $2676.45^{\mathrm{a}}$ & $2110.36^{b}$ & $3035.32^{\mathrm{c}}$ & $3661.93^{\mathrm{d}}$ & $4261.93^{\mathrm{e}}$ & $100.410^{* * *}$ \\
\hline Active Fe (mg/kg) & $0.18^{\mathrm{a}}$ & $0.14^{\mathrm{b}}$ & $0.21^{\mathrm{c}}$ & $0.31^{\mathrm{d}}$ & $0.4^{\mathrm{e}}$ & $107.173^{* * *}$ \\
\hline Active $\mathrm{Mn}(\mathrm{mg} / \mathrm{kg})$ & $0.01^{\mathrm{a}}$ & $0.12^{\mathrm{b}}$ & $0.14^{\mathrm{c}}$ & $0.12^{\mathrm{b}}$ & $0.02^{\mathrm{a}}$ & $568.706^{* * *}$ \\
\hline Total Ca $(\mathrm{g} / \mathrm{kg})$ & $312.13^{\mathrm{abc}}$ & $323.2^{\mathrm{a}}$ & $305.36^{\mathrm{b}}$ & $310.6^{\mathrm{bc}}$ & $320.6^{\mathrm{ac}}$ & $3.096^{* *}$ \\
\hline Total Mg (g/kg) & $136.35^{\mathrm{a}}$ & $200.32^{\mathrm{b}}$ & $152.68^{c}$ & $190.48^{b}$ & $170.48^{d}$ & $73.745^{* * *}$ \\
\hline Total Al (g/kg) & $66.16^{\mathrm{a}}$ & $75.72^{\mathrm{b}}$ & $80.72^{\mathrm{c}}$ & $82.97^{c}$ & $8.97^{\mathrm{d}}$ & $345.0861^{* * *}$ \\
\hline Total Fe (g/kg) & $20.69^{\mathrm{a}}$ & $15.85^{\mathrm{b}}$ & $18.54^{\mathrm{c}}$ & $20.9^{\text {ad }}$ & $21.9^{\mathrm{d}}$ & $38.423^{* * *}$ \\
\hline Total Mn (g/kg) & $0.34^{\mathrm{a}}$ & $0.35^{\mathrm{a}}$ & $0.43^{b}$ & $0.41^{\mathrm{c}}$ & $0.39^{d}$ & $40.573^{* * *}$ \\
\hline
\end{tabular}

Data for this table are the average of six repetitions. Data in the same line followed by the same letter are not significantly different at $5 \%$ level of probability (Duncan's multiple comparisons test). F-ratios indicating statistical significance at $* * * \mathrm{p}<0.001$, $* * \mathrm{p}<0.01$ and $* \mathrm{p}<0.05$.

significantly lower than those in FSSFG and FSFGF. Total porosity in SSFGF and FSFGF was significantly lower than those in the other three substrates, but the difference between FSSGF, FSSFF, and FSSFG, and SSFGF and FSFGF was not significant. $\mathrm{K}_{80}$ uniformity coefficient was significantly lower in SSFGF than that in the other four substrates and it was significantly greater in FSSFG than that in the other four substrates, but the difference between SSFGF and FSFGF, FSSGF and FSFGF, and FSSFF and FSSFG was not significant. $\mathrm{pH}$ was not significantly different between FSSGF and FSFGF and was significantly greater than that in the other three. It was significantly lower in SSFGF than that in the other four. It was significantly greater in FSSFF than in FSSFG, and significantly lower than in FSSGF and FSFGF. The cation exchange capacity (CEC) was significantly greater in substrate SSFGF than that in the other four substrates, but the difference between FSSGF, FSSFF, FSSFG, and FSFGF was not significant. Exchangeable Mg was not significantly different between FSSFF and FSFGF, and was significantly lower than in the other three. It was significantly greater in FSSGF than in SSFGF, and significantly lower than in FSSFG.
Exchangeable Al and Active Fe were significantly different in the five substrates, and the order of the content was as follows: FSFGF $>$ FSSFG $>$ FSSFF $>$ SSFGF $>$ FSSGF. Total Mg was not significantly different between FSSGF and FSSFG and was significantly greater than that in the other three. It was significantly lower in FSSFF than that in FSFGF, and significantly greater in SSFGF. Total Fe in FSSFF was significantly lower than in SSFGF, FSSFG, and FSFGF, and was significantly greater in FSSGF, but the difference between SSFGF and FSSFG was not significant and the content was significantly lower than in FSFGF; the difference between FSSGF and FSFGF was not significant.

\section{$\mathrm{Pb}$ Removal Efficiency of Mixed Substrates}

Results indicated effluent concentrations of $\mathrm{Pb}$ from the five substrates were affected, but the effects varied with substrates for $\mathrm{Pb}$ levels at five initial concentrations and at $48 \mathrm{~h}$ (Table 3). It was found that for five substrates there was no significant difference among $10 \mathrm{mg} / \mathrm{L}$ and $40 \mathrm{mg} / \mathrm{L}$ initial concentrations ( $p>0.05$ ). The content of $\mathrm{Pb}$ concentration of effluent from five substrates stayed 
Table 3. Pb concentrations of effluent from vertical subsurface flow constructed wetland using mixed substrates.

\begin{tabular}{|c|c|c|c|c|c|c|}
\hline Initial concentration $(\mathrm{mg} / \mathrm{L})$ & SSFGF & FSSGF & FSSFF & FSSFG & FSFGF & F-value \\
\hline 10 & 2.41 & 3.92 & 2.50 & 4.91 & 3.92 & 1.711 \\
\hline 20 & $2.03^{\mathrm{a}}$ & $2.18^{\mathrm{a}}$ & $1.98^{\mathrm{a}}$ & $6.75^{\mathrm{b}}$ & $5.12^{\mathrm{c}}$ & $42.334^{* * *}$ \\
\hline 40 & 3.01 & 3.65 & 3.78 & 3.97 & 4.43 & 1.530 \\
\hline 80 & $12.57^{\mathrm{ad}}$ & $66.88^{\mathrm{b}}$ & $6.38^{\mathrm{a}}$ & $25.29^{\mathrm{c}}$ & $20.61^{\text {cd }}$ & $44.267^{* * *}$ \\
\hline 160 & $44.91^{\mathrm{a}}$ & $79.15^{\mathrm{b}}$ & $32.30^{\mathrm{a}}$ & $33.03^{\mathrm{a}}$ & $50.98^{\mathrm{a}}$ & $10.247^{* * *}$ \\
\hline
\end{tabular}

Data for this table are the average of six repetitions. Data in the same line followed by the same letter are not significantly different at $5 \%$ level of probability (Duncan's multiple comparisons test). F-ratios indicating statistical significance at $* * * \mathrm{p}<0.001, * * \mathrm{p}<0.01$ and $* \mathrm{p}<0.05$

relatively constant at $2.4-4.9 \mathrm{mg} / \mathrm{L}$ and $3.0-4.5 \mathrm{mg} / \mathrm{L}$, respectively, at $10 \mathrm{mg} / \mathrm{L}$ and $40 \mathrm{mg} / \mathrm{L}$ initial concentration. For the other three initial concentrations from five substrates a significant difference was found $(\mathrm{p}<0.001)$. The content of $\mathrm{Pb}$ concentration of effluent from five substrates stayed relatively constant at $1.9-6.8 \mathrm{mg} / \mathrm{L}$, $6.3-66.8 \mathrm{mg} / \mathrm{L}$ and $32.3-79.2 \mathrm{mg} / \mathrm{L}$, respectively, at $20 \mathrm{mg} / \mathrm{L}, 80 \mathrm{mg} / \mathrm{L}$, and $40 \mathrm{mg} / \mathrm{L}$ initial concentration.

At the $\mathrm{Pb}$ initial concentration of $20 \mathrm{mg} / \mathrm{L}$, the $\mathrm{Pb}$ concentration was not significantly different between substrates SSFGF, FSSGF, and FSSFF, and was significantly lower than that in the other two substrates. The $\mathrm{Pb}$ concentration was significantly greater in FSSFG than that in the other four substrates, and it was significantly lower in FSFGF than that in FSSFG, and significantly greater in the other three substrates.

At the $\mathrm{Pb}$ initial concentration of $80 \mathrm{mg} / \mathrm{L}$, the $\mathrm{Pb}$ concentration was significantly greater in FSSFG than in the other four substrates. The difference between SSFGF and FSSFF was not significant, and the $\mathrm{Pb}$ concentration in FSSFF was significantly lower than that in the other substrates. The difference between FSSFG and FSFGF was not significant, and it was significantly lower than that in FSSGF and greater than that in the other three substrates. The difference between SSFGF and FSFGF was not significant.

At the $\mathrm{Pb}$ initial concentration of $160 \mathrm{mg} / \mathrm{L}$, the $\mathrm{Pb}$ concentration was greater in FSSGF than in the other four substrates. The difference between SSFGF, FSSFF, FSSFG, and FSFGF was significant, and the $\mathrm{Pb}$ concentration was significantly lower than in FSSGF. The amounts of $\mathrm{Pb}$ decreased in the sequence of FSSGF $>$ FSFGF $>$ SSFGF $>$ FSSFG $>$ FSSFF at the $\mathrm{Pb}$ level of $160 \mathrm{mg} / \mathrm{L}$ and after $48 \mathrm{~h}$ operation.

\section{$\mathrm{Pb}$ Removal Process of Mixed Substrates}

The percentage removal of $\mathrm{Pb}$ from solution by the five substrates at five different initial $\mathrm{Pb}$ concentrations varied with operation time (Fig. 2). At the beginning of 4h, there were no clear regularities in $\mathrm{Pb}$ removal between the systems, and all the systems exhibited greater fluctuations.

During the first $1 \mathrm{~h}$, the removal efficiency of SSFGFbased wetland was lower than those of the other substrate- based wetlands, until the ultimate time it was better than those. From $0.5 \mathrm{~h}$ to $8 \mathrm{~h}$, the removal efficiency increased differently and continually decreased in the following time. Before the first $8 \mathrm{~h}$, the higher removal efficiency of $\mathrm{Pb}$ was found in the SSFGF-based wetland, it reached the maximum $92.94 \%$ at $4 \mathrm{~h}$ operation time, and subsequently the removal efficiency decreased, reaching the minimum on-time $12 \mathrm{~h}$ and then increased differently in the following time. Afterward, the slightly better removal efficiency was found in the FSSFF-based wetland. Removal efficiency increased after reaching the minimum values at $2 \mathrm{~h}$ for FSSFF-based wetland. All the constructed wetlands performed well and the removal efficiencies were almost all above $80 \%$. The removal efficiency of the SSFGFbased wetland was better than those of the other substratebased wetlands. During the decomposition period, the efficiency decreased differently and reached the minimum values in $12 \mathrm{~h}$. Besides, the removal efficiency of the FSFGF-based wetland was better than that of the FSSFFbased wetland between $2 \mathrm{~h}$ and $10 \mathrm{~h}$; in the following time it was better in the latter.

At the beginning of $8 \mathrm{~h}$, the removal efficiency was greater in the SSFGF-based wetland, it increased differently and reached maximum values at $4 \mathrm{~h}$. The efficiency decreased differently in the following time. And after $8 \mathrm{~h}$, greater removal efficiency was found in the FSSFF-based wetland. The inverse phenomena were observed in the FSSFF-based wetland contrary to SSFGF. The removal efficiency of FSSFF-based wetland was better than those of the other substrate-based wetlands. From $0.5 \mathrm{~h}$ to $2 \mathrm{~h}$, it increased significantly and reached the maximum values at $2 \mathrm{~h}$, but subsequently it decreased differently. Next, the greater removal efficiency was found in SSFGF-based wetland. And during the whole $48 \mathrm{~h}$ decomposition period efficiency decreased differently (Fig. 2).

Removal of $\mathrm{Pb}$ by five mixed substrates was investigated in this study. Of the five substrates, SSFGF had the higher removal capacity and then it was FSSFF. The removal efficiency was better for SSFGF than other substrates at low and medium initial concentrations (i.e., $10 \mathrm{mg} / \mathrm{L}, 20 \mathrm{mg} / \mathrm{L}, 40 \mathrm{mg} / \mathrm{L}$, and $80 \mathrm{mg} / \mathrm{L}$ ), primarily it didn't constitute fly ash. The contents of hydraulic conductivity and total porosity were suitable and didn't 
cause clogging of wetland due to their swelling nature. Experimental results indicated that it found a "trade off" point between treatment efficiency and hydraulic conductivity. Although the content of total porosity as with SSFGF, FSFGF had a higher hydraulic conductivity and the contact time with substrate was short, resulting in lower efficiency. In addition, the range of $\mathrm{pH}$ had an influence on efficiency. For instance, lead reacted

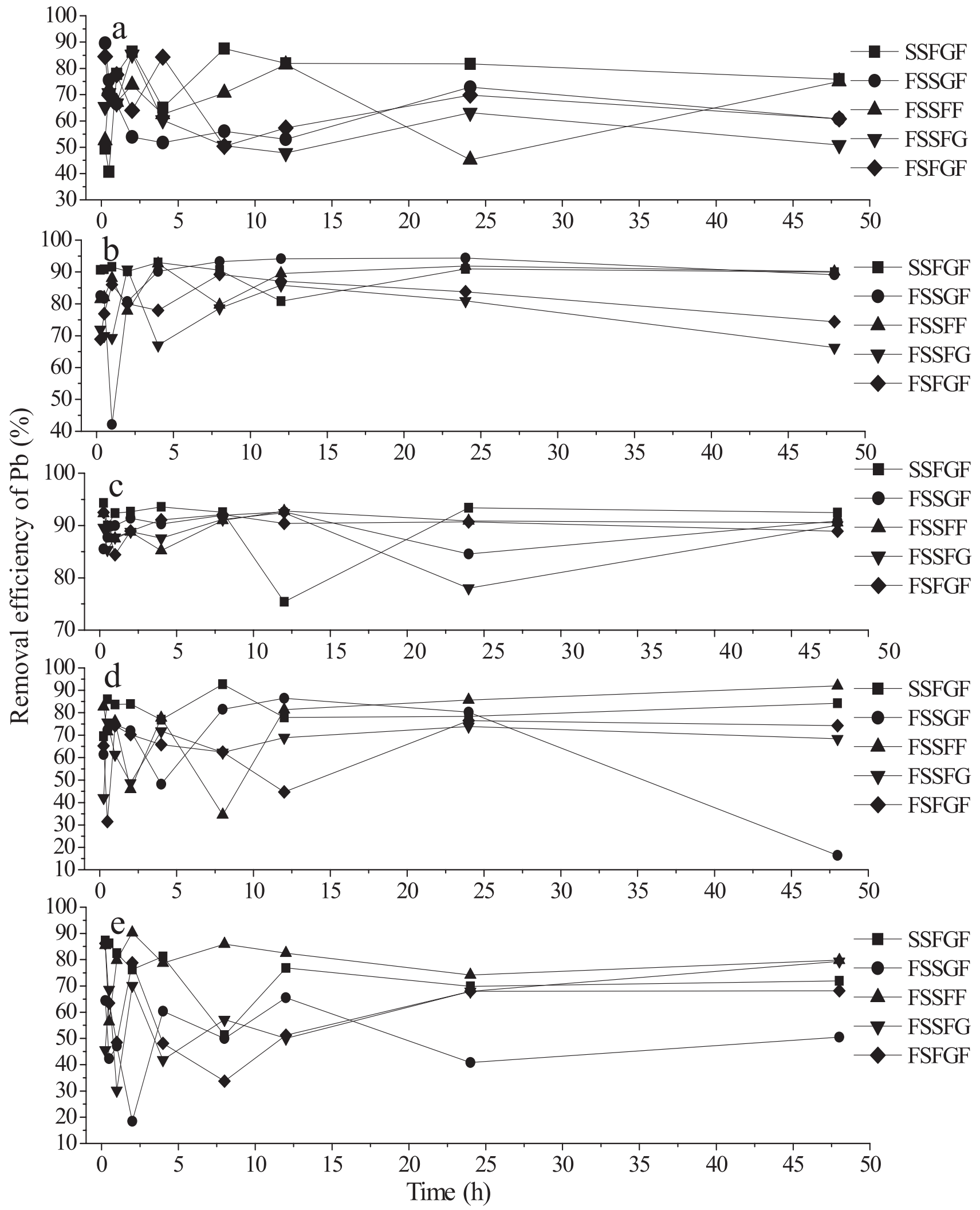

Fig. 2. Removal of $\mathrm{Pb}$ in $10 \mathrm{mg} / \mathrm{L}$ (a), $20 \mathrm{mg} / \mathrm{L}$ (b), $40 \mathrm{mg} / \mathrm{L}$ (c), $80 \mathrm{mg} / \mathrm{L}$ (d), and $160 \mathrm{mg} / \mathrm{L}$ (e) initial concentrations under unvegetated vertical subsurface flow constructed wetland using mixed substrates. 
with hydro ion to form lead hydroxide under high $\mathrm{pH}$ conditions, and lead hydroxide could be precipitated out of solutions. On the other hand, the higher the $\mathrm{pH}$, the easier it was clogged. The conclusion was confirmed in substrate FSSGF at high initial concentrations. So the suitable range of $\mathrm{pH}$ was 8-10 in this study. For FSSFG, pH was 8.92; the efficiency was poor likely due to the highest contents of hydraulic conductivity resulting in precipitates washed away by water.

At relatively high initial concentrations $(160 \mathrm{mg} / \mathrm{L})$, the removal efficiency was better for substrate FSSFF than other substrates; probably it didn't constitute gravel. This result indicated that although gravel improved the hydraulic conductivity of the system and delayed clogging time, it did not increase efficiency. In addition, the ability of $\mathrm{Pb}$ removal by a substrate was somehow determined by the contents of total Fe, exchangeable $\mathrm{Al}$, and active $\mathrm{Fe}$ - especially the contents of active Fe, total $\mathrm{Fe}$, and exchangeable $\mathrm{Al}$ over a short time. The lower the contents of exchangeable $\mathrm{Mg}$ and total $\mathrm{Mg}$, the higher the efficiency. The CEC of a substrate also plays an important role in $\mathrm{Pb}$ removal. The maximum content of CEC showed the better removal efficiency at low and medium initial concentrations, and so was the minimum content of CEC at high concentrations.

\section{Conclusions}

For five substrates, the effluent concentrations were not significantly different among $10 \mathrm{mg} / \mathrm{L}$ and $40 \mathrm{mg} / \mathrm{L}$ initial concentrations. For the other three initial concentrations (20 mg/L, $80 \mathrm{mg} / \mathrm{L}$, and $160 \mathrm{mg} / \mathrm{L}$ ) from five substrates, there was a very significant difference.

The removal efficiency of $\mathrm{Pb}$ from the solution was better for SSFGF-based wetland than those of the other substrate-based wetlands at low and medium initial concentrations $(10 \mathrm{mg} / \mathrm{L}, 20 \mathrm{mg} / \mathrm{L}, 40 \mathrm{mg} / \mathrm{L}$, and $80 \mathrm{mg} / \mathrm{L})$, and then it was slightly better for FSSFF-based wetland. At relatively high initial concentrations $(160 \mathrm{mg} / \mathrm{L})$, the removal efficiency was better for FSSFF-based wetland than those of the other substrate-based wetlands, and then it was slightly better for SSGFF-based wetland.

For the physicochemical properties of the five substrates, active $\mathrm{Fe}$, total $\mathrm{Fe}$, and exchangeable $\mathrm{Al}$ showed moderate contents with better removal efficiency of $\mathrm{Pb}$, and hydraulic conductivity, total porosity, $\mathrm{pH}$, exchangeable $\mathrm{Mg}$, and total $\mathrm{Mg}$ showed low and medium contents with better removal efficiency of $\mathrm{Pb}$, whereas the maximum content of CEC showed the better removal efficiency at low and medium initial concentrations, as was the minimum content of CEC at high concentrations.

\section{Acknowledgements}

This project was supported by the Program for Changjiang Scholars and Innovative Research Team in the University of the Ministry of Education of China
(No. IRT0966), by grants from the Science and Technology Develops Project in Lanzhou (No. 12C26216207079), and by the Special Fund Project of Fundamental Business Research of Gansu Province High School (No. 212095).

\section{References}

1. ZHANG M., CUI L., SHENG L., WANG Y. Distribution and enrichment of heavy metals among sediments, water body and plants in Hengshuihu wetland of northern China. Ecological Engineering, 35 (4), 563, 2009.

2. LANGERGRABER G. Are constructed treatment wetlands sustainable sanitation solutions? Water Science and Technology, 67, 2133, 2013.

3. ZHI W., JI G. Constructed wetlands, 1991-2011: a review of research development, current trends, and future directions. Science of the Total Environment, 441, 19, 2012.

4. VYMAZAL J. Constructed wetlands for wastewater treatment: five decades of experience. Environmental Science and Technology, 45 (1), 61, 2011.

5. DI LUCA G.A., MAINE M.A., MUFFARREGE M.M., HADAD H.R., SÁNCHEZ G.C., BONETTO C.A. Metal retention and distribution in the sediment of a constructed wetland for industrial wastewater treatment. Ecological Engineering, 37, 1267, 2009.

6. CHOUDHARY A.K., KUMAR S., SHARMA C. Removal of chlorinated resin and fatty acids from paper mill wastewater through constructed wetland. World Academy Science and Engineering Technology, 80, 67, 2010.

7. FIBBI D., DOUMETT S., COLZI I., COPPINI E., PUCCI S., GONNELLI C., LEPRI L., DEL BUBBA M. Total and hexavalent chromium removal in a subsurface horizontal flow (h-SSF) constructed wetland operating as post-treatment of textile wastewater for water reuse. Water Science and Technology, 64 (4), 826, 2011.

8. KHAN S., AHMAD I., SHAH T.M., REHMAN S., KHALIQ A. Use of constructed wetland for the removal of heavy metals from industrial wastewater. Journal of Environmental Management, 90, 3451-3457, 2009.

9. DOTRO G., PALAZOLO P., LARSEN D. Chromium fate in constructed wetlands treating tannery wastewaters. Water Environmental Research, 81 (6), 617, 2009.

10. XU J.C., CHEN G., HUANG X.F., LI G.M., LIU J., YANG N., GAO S.N. Iron and manganese removal by using manganese ore constructed wetlands in the reclamation of steel wastewater. Journal of Hazardous Materials, 169, 309, 2009.

11. YALCUK A., UGURLU A. Comparison of horizontal and vertical constructed wetland systems for landfill leachate treatment. Bioresource Technology, 100, 2521, 2009.

12. SCHOLZ M., HEDMARK A. Constructed wetlands treating runoff contaminated with nutrients, Water Air and Soil Pollution, 205, 323, 2010.

13. WOOD R.B., MCATAMNEY C.F. Constructed wetlands for waste water treatment: the use of laterite in the bed medium in phosphorus and heavy metal removal. Hydrobiologia, 340, 323, 1996.

14. CHEN M.Z., TANG Y.Y., LI X.P., YU, Z.X. Study on the heavy metals removal efficiencies of constructed wetlands with different substrates. Journal of water Resource and Protection, 1, 1, 2009.

15. ALLENDE L.K., FLETCHER T.D., SUN G. Enhancing the removal of arsenic, boron and heavy metals in subsurface flow constructed wetlands using different supporting media. Water Science and Technology, 63 (11), 2612, 2011. 
16. GALLETTI A., VERLICCHI P., RANIERI E. Removal and accumulation of $\mathrm{Cu}, \mathrm{Ni}$ and $\mathrm{Zn}$ in horizontal subsurface flow constructed wetlands: Contribution of vegetation and filling medium. Science of the Total Environment, 408, 5097, 2010.

17. SCHOLZ M., XU J. Performance comparison of experimental constructed wetlands with different filter media and macrophytes treating industrial wastewater contaminated with lead and copper. Bioresource Technology, 83, 71-79, 2002.
18. FORBES M.G. Phosphorus retention and fractionation in masonry sand light weight expanded shale used as substrate in constructed wetland systems. Water Research, 33 (17), 3595, 2002.

19. CUI L.H., ZHU X.Z., MA M., OUYANG Y., DONG M., ZHU W.L., LUO S.M. Phosphorus sorption capacities and physicochemical properties of nine substrate materials for constructed wetland. Archives of Environmental Contamination and Toxicology, 55, 210, 2008. 